\title{
Systemic Inflammatory Response Syndrome
}

National Cancer Institute

\section{Source}

National Cancer Institute. Systemic Inflammatory Response Syndrome. NCI Thesaurus.

Code C94832.

A generalized state of dysregulated inflammation induced by noninfectious processes. It is characterized by two or more of the following signs and symptoms: fever or hypothermia, increased heart rate, increased respiratory rate, and abnormal white blood cell count. 